Article

\title{
The Effect of a Secondary Task on Kinematics during Turning in Parkinson's Disease with Mild to Moderate Impairment
}

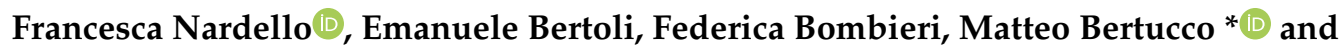 \\ Andrea Monte ${ }^{D}$ \\ Department of Neurosciences, Biomedicine and Movement Sciences University of Verona, 43, 37131 Verona, \\ Italy; francesca.nardello@univr.it (F.N.); emanuele.bertoli@studenti.univr.it (E.B.); \\ federica.bombieri@univr.it (F.B.); andrea.monte@univr.it (A.M.) \\ * Correspondence: matteo.bertucco@univr.it; Tel.: +39-045-8425131
}

Received: 10 July 2020; Accepted: 29 July 2020; Published: 3 August 2020

check for updates

\begin{abstract}
Patients with Parkinson's disease (PD) show typical gait asymmetries. These peculiar motor impairments are exacerbated by added cognitive and/or mechanical loading. However, there is scarce literature that chains these two stimuli. The aim of this study was to investigate the combined effects of a dual task (cognitive task) and turning (mechanical task) on the spatiotemporal parameters in mild to moderate PD. Participants (nine patients with PD and nine controls (CRs)) were evaluated while walking at their self-selected pace without a secondary task (single task), and while repeating the days of the week backwards (dual task) along a straight direction and a $60^{\circ}$ and $120^{\circ}$ turn. As speculated, in single tasking, PD patients preferred to walk with a shorter stride length $(p<0.05)$ but similar timing parameters, compared to the CR group; in dual tasking, both groups walked slower with shorter strides. As the turn angle increased, the speed will be reduced $(p<0.001)$, whereas the ground-foot contact will become greater $(p<0.001)$ in all the participants. We showed that the combination of a simple cognitive task and a mechanical task (especially at larger angles) could represent an important training stimulus in PD at the early stages of the pathology.
\end{abstract}

Keywords: Parkinson's disease; gait; dual task; turning; kinematics

\section{Introduction}

Gait functionality is accomplished with good health, whereas locomotion disturbances are associated with an advancing age or with the presence of pathologies. Within 3 years of diagnosis, over 85\% of people with Parkinson's disease (PD) develop gait deteriorations [1,2], as well as a reduced walking symmetry [2-4]. Such motor dysfunctions could be exacerbated under various conditions, such as the dual task performance and the changing of the walking direction (i.e., turning).

Specifically, the execution of the two tasks simultaneously ("concurrent performance") presents a challenge for PD patients because of their disabled lower-level spinal centers and basal nuclei [5-7]. Studies have shown that, when compared to controls, subjects with PD show greater reductions in their stride length [8,9] and, therefore, walking speed, as well as an increased variability of the kinematic parameters [10-16]. These patterns are aggravated with the severity of the pathology [17,18] and with the complexity of the concurrent task $[5,13,19,20]$. Since these findings strengthen the idea that the cognitive function could contribute to gait regulation, it could be helpful to understand the effect of different cognitive tasks, even very simple ones, in this kind of pathology [21-23]. This knowledge could provide an insight on what is the best training stimulus to be administered in those patients. 
Concerning the walking direction, it has been shown that subjects with PD report turning difficulties, which are associated with an augmented risk of falling [24-27]. These impairments are due to the central nervous system's involvement in body re-orientation when travelling in the new direction.

From a kinematical point of view, patients with PD highlighted a smaller step width $[9,28]$, a reduction in the step length and a decrease in their walking velocity during a change of direction of $45^{\circ}$ in the stepping tasks [29]. If the turning angle increased (i.e., to $90^{\circ}$ ), patients approached turns with a slower step length and by performing the turn with a larger number of steps [30]. Walking with an auditory cue reduced the gait-timing variability, as well as the step length, and increased the radius of gyration during a turn of $180^{\circ}$ [31]. Moreover, recent literature has shown that subjects with PD spent more time during the turn (between $30^{\circ}$ and $180^{\circ}$ ) and exhibit a reduction in the walking stability compared to controls [32]. Turning $360^{\circ}$ in place seemed to be a more compromised condition when compared to turning while walking, with similar impairments with and without episodes of freezing $[33,34]$. As in the case of the cognitive additional demand, the turning conditions could also represent an important stimulus in such a population. Hence, investigating different turning conditions could provide important information about the optimal training strategy in people with PD.

To date, a lingering question in the literature regards the combination of mechanical and cognitive perturbations. Indeed, few studies have combined the dual task condition with the mechanical perturbations (e.g., change of direction) [35-37]. Furthermore, previous studies usually used turn angles larger than $90^{\circ}$, which represents per se an important perturbation for PD patients [30].

Therefore, we used the most common turning angles during daily life $\left(60^{\circ}\right.$ and $\left.120^{\circ}\right)$ [38], in combination with a simple cognitive task (repeating the days of the week backwards), to better understand the effects of these perturbations on gait kinematics. This combined approach has involved participants with mild to moderate PD in order to provide additional information on how the typical Parkinson's disease walking pattern is modified under simultaneous cognitive and mechanical loads.

Hence, the primary aim was to investigate if the presence of a "dual task" condition can further alter the kinematics (i.e., spatiotemporal parameters) of walking, or, on the contrary, if it can represent a good training stimulus in mild and moderate Parkinson's disease. This cognitive task was studied during forward/linear walking and during turning.

Based on the previously mentioned literature, we hypothesized that the simple cognitive and the mechanical tasks will exhibit similar effects in both populations (patients and controls), whereas the combination of the two stimuli will show a higher impact on PD patients.

\section{Materials and Methods}

\subsection{Participants}

This study has a cross-sectional, analytical, observational design. Nine patients with mild to moderate PD ( 3 women and 6 men; mean \pm SD, $68.2 \pm 5.95$ years old, $74.2 \pm 11.8 \mathrm{~kg}$ body mass, $1.70 \pm 0.10 \mathrm{~m}$ height, and $25.6 \pm 3.07 \mathrm{~kg} \cdot \mathrm{m}^{-2}$ body mass index (BMI)) and nine healthy age-matched controls ( 4 women and 5 men; $67.2 \pm 3.45$ years old, $72.6 \pm 13.1 \mathrm{~kg}, 1.68 \pm 0.08 \mathrm{~m}$, and $25.7 \pm 3.43 \mathrm{~kg} \cdot \mathrm{m}^{-2}$ ) were recruited in this study.

All participants received written and oral instructions before the study and gave their written informed consent for the experimental procedure. The study was conducted in accordance with the Declaration of Helsinki, and the experimental protocol was approved by the Institutional Review Board of the Department of Neurosciences, Biomedicine and Movement Sciences, University of Verona (protocol number 2018-UNVRCLE-0451799).

Participants were recruited from a sample of late adulthood people attending the adapted physical activity program at the School of Sport and Exercise Science at our University (see their characteristics in Table 1). 
Table 1. Characteristics of subjects with Parkinson's disease.

\begin{tabular}{|c|c|c|c|c|c|c|c|c|c|c|c|}
\hline $\begin{array}{c}\text { Subject } \\
\text { No. }\end{array}$ & $\begin{array}{l}\text { Age } \\
\text { (yrs) }\end{array}$ & Sex & $\begin{array}{l}\text { Body } \\
\text { Mass } \\
(\mathbf{k g})\end{array}$ & $\begin{array}{l}\text { Body } \\
\text { Height } \\
\text { (m) }\end{array}$ & $\begin{array}{c}\text { BMI } \\
\left(\mathrm{kg} \cdot \mathrm{m}^{-2}\right)\end{array}$ & $\begin{array}{c}\text { Disease } \\
\text { Duration } \\
\text { (yrs) }\end{array}$ & $\begin{array}{l}\text { Y\&H } \\
\text { Score }\end{array}$ & $\begin{array}{l}\text { UPDRS } \\
\text { Score }\end{array}$ & MMSE & Medication & $\begin{array}{c}\text { Side of Appearance of } \\
\text { the First Motor } \\
\text { Symptom }\end{array}$ \\
\hline PD1 & 77 & $\mathrm{~F}$ & 80 & 1.64 & 29.74 & 4 & 1 & 26 & 29 & Levodopa/carbidopa & Left \\
\hline PD3 & 71 & $\mathrm{M}$ & 70 & 1.70 & 24.22 & 3 & 1 & 24 & 28 & Levodopa/benserazide & Right \\
\hline PD4 & 59 & $\mathrm{M}$ & 65 & 1.70 & 22.49 & 9 & 1 & 26 & 29 & Levodopa/carbidopa & Left \\
\hline PD5 & 67 & $\mathrm{M}$ & 80 & 1.66 & 29.03 & 3 & 1 & 30 & 26 & Levodopa/carbidopa & Right \\
\hline PD6 & 67 & $\mathrm{M}$ & 80 & 1.77 & 25.54 & 6 & 1 & 30 & 28 & Levodopa/benserazide & Left \\
\hline PD8 & 77 & $\mathrm{M}$ & 82 & 1.88 & 23.20 & 8 & 1 & 25 & 24 & Levodopa/carbidopa & Right \\
\hline PD9 & 67 & M & 93 & 1.78 & 29.35 & 7 & 2 & 32 & 25 & Levodopa/carbidopa & Left \\
\hline
\end{tabular}

BMI: body mass index; Y\&H: Hoehn and Yahr; UPDRS: Unified Parkinson's Disease Rating Scale (motor section); MMSE: Mini Mental State Education. 
Patients were excluded if their medical condition proved unstable due to other neurological, orthopedic, metabolic or cardiovascular co-morbidity factors affecting gait. There was no type of rehabilitation in the month prior to recruitment or disease-modifying therapy that was not well defined. A diagnosis of idiopathic PD was carried out by a neurologist, in accordance with the guidelines established by the London Brain Bank [39]. The disease severity was classified according to the modified Hoehn and Yahr scale (H\&Y) [40], whereas the assessment of the degree of motor and functional impairment was obtained using part III of the Unified Parkinson's Disease Rating Scale (UPDRS) [41]. Finally, cognitive function was assessed by using the Mini Mental State Examination (MMSE), with scores of up to 30 (higher scores correspond to greater cognitive function).

We conducted an a priori screening to evaluate whether participants were able to carry out the task instructions required for the experimental protocol (see the "Experimental procedures" later). Based on this a priori screening, only individuals with PD with an MMSE score of 24 or higher were able to perform the double stimuli, and therefore were recruited in the study.

\subsection{Experimental Procedures}

Tests were conducted in the Biomechanics Laboratory at the Department of Neurosciences, Biomedicine and Movement Sciences. The spatial (distance) and temporal (time) characteristics of the step pattern were measured using an eight-camera motion capture system (MX Ultranet, VICON, Oxfordshire, UK), sampling at $100 \mathrm{~Hz}$. This apparatus recorded the position of markers positioned bilaterally on the feet: the calcaneus, lateral malleolus and 5th metatarsal-phalangeal joint.

Participants started from a standing position and walked barefoot at their self-selected speed over a $10 \mathrm{~m}$ walkway (Figure 1, panel a). Each participant performed three different conditions: (i) forward walking (WF (Figure 1, panel b)); (ii) walking, turning at $60^{\circ}$, walking (T60); (iii) walking, turning at $120^{\circ}$, walking (T120). Furthermore, T60 and T120 were conducted turning in both directions (left and right (Figure 1, panels c and d)). During all turning tasks, a cone was positioned in the center of the walkway (see the black hexagon in Figure 1) to identify the turning point. Furthermore, an operator positioned himself at the end of the corridor lane that the subjects had to move. All directions were tested in single and dual tasks, and the cognitive load consists of walking while repeating the days of the week backwards [17]. Six trials of each condition were performed and the order of gait conditions was randomly allocated (Figure 2). Subjects sat and rested in a chair for three minutes between trials. Patients were tested at the peak dose in the medication cycle.

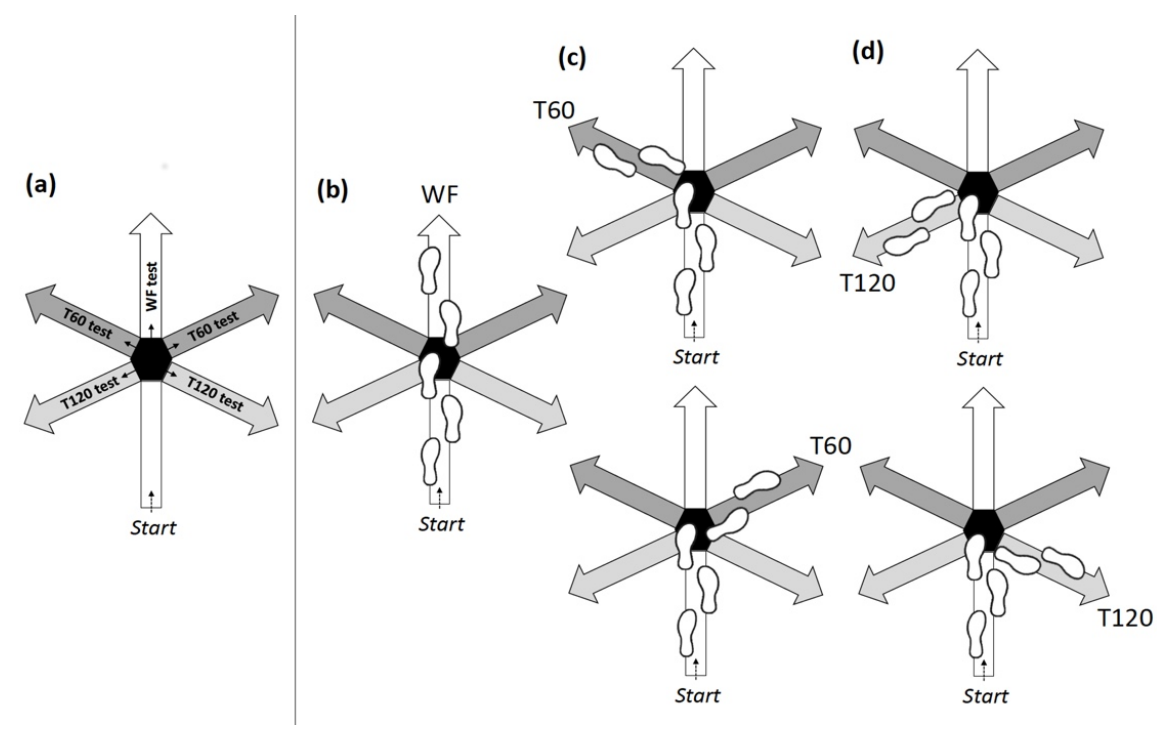

Figure 1. Schematic representation of walking conditions (a), and steps during walking (forward walking (WF), (b) and turning (T60 in (c) and T120 in (d)). 


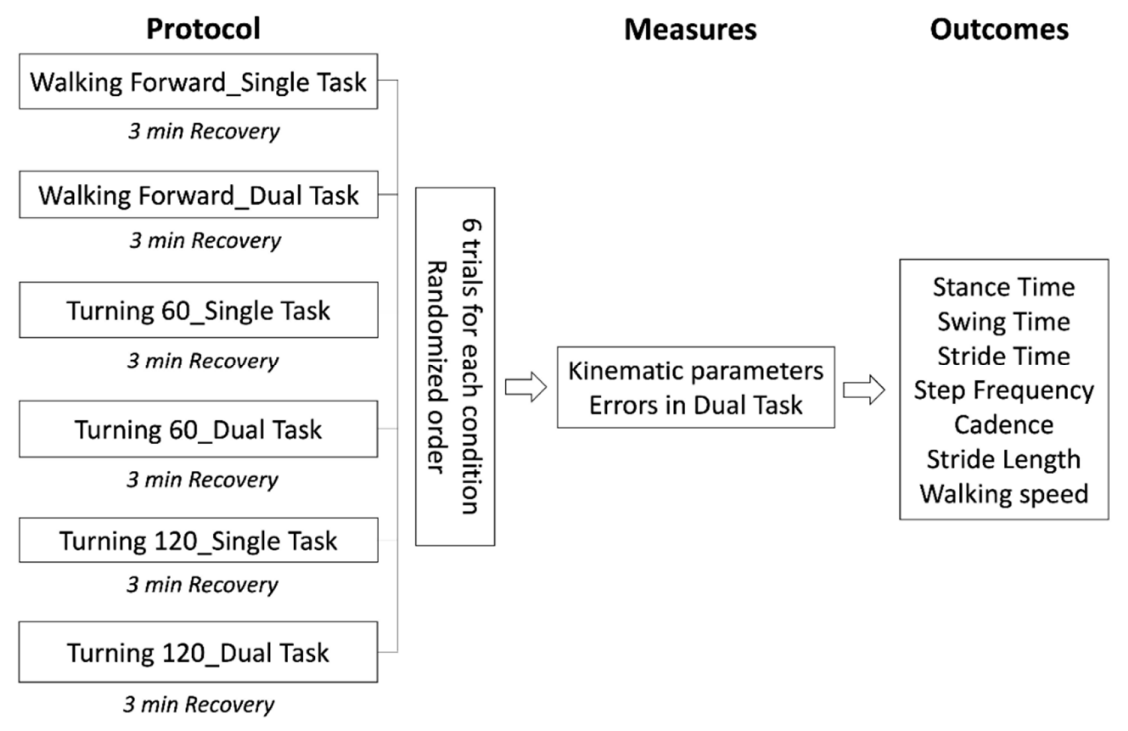

Figure 2. Flow chart of the research design.

\subsection{Data Reduction}

Kinematic data were recorded from $3 \mathrm{~m}$ before and after the turning step. The quantitative gait assessment included both temporal and spatial parameters (Figure 3), that are: (i) stance time (s), the period of time when the foot is in contact with the ground; (ii) swing time (s), the period of time when the foot is not in contact with the ground; (iii) stride time (s), the interval of time to complete a gait stride; $(i v)$ cadence (stride $\mathrm{min}^{-1}$ ), the number of strides taken in a unit of time; $(v)$ stride length $(\mathrm{m})$, the distance from the initial contact of one foot to the following initial contact of the same foot. All these parameters were obtained using standard definitions according to an algorithm programmed in LabView (version 10, National Instruments, Austin, TX, USA). Walking speed $\left(\mathrm{m} \cdot \mathrm{s}^{-1}\right)$ was appreciated as the distance travelled during a complete stride cycle.

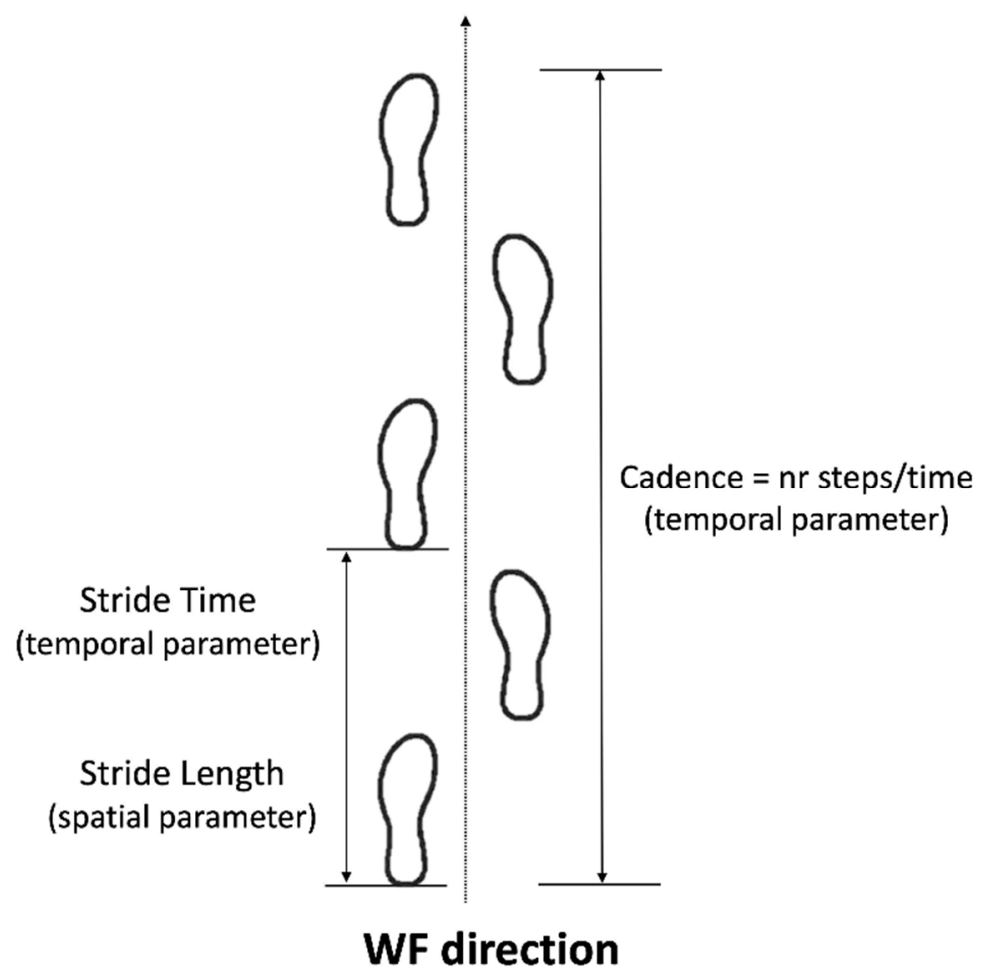

Figure 3. Gait parameter assessment for walking/turning conditions. 
The average value of all the performed steps in each condition has been utilized in further analyses. The number of errors (i.e., when telling a day backwards went wrong) was counted and collected by an operator during the walking trials as well. For controls, we pooled together the data from the right and left lower limbs $(n=9)$, whereas for PD patients, the data referring to the less affected side (PDNA) and to the more affected side (PDA) were considered separately $(n=9)$.

Finally, we calculated the locomotor rehabilitation index "LRI" as: LRI $=100$ * (self-selected speed (SSWS)/optimal speed (OWS)), where the self-selected speed (SSWS) has been directly measured and the optimal speed (OWS) has been estimated according to a previous study [42].

\subsection{Data Analysis}

The data analysis was conducted using SPSS 19.0 (SPSS Inc, Chicago, IL, USA). Descriptive statistics were used to compute the means and standard deviations for the outcome variables. All the spatiotemporal gait data were normally distributed (Kolmogorov-Smirnov and Shapiro-Wilk tests) and did not violate the assumptions of homogeneity. In order to test the main hypotheses, a series of 2 (tasks: single task vs. dual task) $\times 3$ (gait directions: WF vs. T60 vs. T120) repeated measures ANOVAs, with groups (CR, PDNA, PDA) as the between factors, were used to analyze the gait data. When a significant main effect was found (critical $p$ value $<0.05$ ), a post-hoc $t$-test was performed. A Bonferroni correction was applied when needed.

\section{Results}

\subsection{Cognitive Task}

For the MMSE, controls $(28.1 \pm 1.66)$ showed similar scores to patients $(27.2 \pm 1.85(\mathrm{p}=\mathrm{ns}))$.

The majority of the dual task trails were successful. Whereas individuals with PD performed the cognitive task with $97.2 \pm 6 \%, 94.9 \pm 8 \%$ and $95.2 \pm 10 \%$ accuracy during WF, T60 and T120, respectively, and controls performed the same trails with an accuracy of $96.7 \pm 5 \%, 95.3 \pm 6 \%$ and $94.9 \pm 9 \%$. Regarding the gait direction, more correct answers were given while walking forward as compared to turning $(p<0.01$ for T60 and T120) similarly in both groups.

\subsection{Spatiotemporal Parameters}

There were no differences between groups for age, body mass and height, or body mass index.

The average \pm SD values of the measured temporal and spatial variables have been reported in Tables 2 and 3, as well as the post-hoc results.

The stance time differed among tasks $(\mathrm{F}(1,24)=34.456, p<0.001)$ and walking direction $(\mathrm{F}(2,48)=27.234, p<0.001)$, whereas there were no differences between groups $(\mathrm{F}(2,24)=0.262$, $\mathrm{p}=\mathrm{ns}$ ). In particular, the dual task showed an increased stance time compared to the single one. The highest stance phase was observed during turning at $120^{\circ}$, while the lowest was during walking in the straight direction.

The swing phase showed a significant effect for direction $(\mathrm{F}(2,48)=4.648, p<0.05)$, but not for $\operatorname{task}(\mathrm{F}(1,24)=3.745, \mathrm{p}=\mathrm{ns})$ and group $(\mathrm{F}(2,24)=0.883, \mathrm{p}=\mathrm{ns})$. Particularly, the $120^{\circ}$ turn took a longer swing time in comparison to the other directions.

The cycle time showed significant differences among tasks $(\mathrm{F}(1,24)=31.840, p<0.001)$ and directions $(F(2,48)=34.227, p<0.001)$, whereas there were no group changes $(F(2,24)=0.618, p=n s)$. Both groups increased the cycle time during the dual task condition, and the $120^{\circ}$ turn took the longest time compared with the other conditions.

Therefore, the step frequency and cadence changed significantly with regard to task $(\mathrm{F}(1,24)=30.257$ and 30.317, $p<0.001)$ and direction $(\mathrm{F}(2,48)=31.329$ and 31.441, $p<0.001)$, but not with group $(\mathrm{F}(2,24)=0.458$ and $0.457, \mathrm{p}=\mathrm{ns})$. 
Table 2. Gait temporal parameters at single and dual tasking in all directions. Data are means \pm SD.

\begin{tabular}{|c|c|c|c|c|c|c|}
\hline \multirow[b]{2}{*}{ Walking Direction } & \multicolumn{3}{|c|}{ Stance Time (s) } & \multicolumn{3}{|c|}{ Swing Time (s) } \\
\hline & CR & PDNA & PDA & CR & PDNA & PDA \\
\hline WF_ST & $0.72 \pm 0.05$ & $0.74 \pm 0.12^{a}$ & $0.74 \pm 0.18^{c, 1}$ & $0.33 \pm 0.03$ & $0.33 \pm 0.04$ & $0.33 \pm 0.02^{a}$ \\
\hline T60_ST & $0.73 \pm 0.07^{\mathrm{a}}$ & $0.76 \pm 0.13^{\mathrm{a}, \mathrm{h}, \mathrm{m}}$ & $0.75 \pm 0.12^{b, g}$ & $0.33 \pm 0.04$ & $0.33 \pm 0.04$ & $0.35 \pm 0.03$ \\
\hline WF_DT & $0.75 \pm 0.07^{\mathrm{m}}$ & $0.80 \pm 0.12^{\mathrm{a}, \mathrm{m}}$ & $0.78 \pm 0.11^{\mathrm{c}, 1}$ & $0.33 \pm 0.04$ & $0.34 \pm 0.04$ & $0.35 \pm 0.05^{\mathrm{a}}$ \\
\hline T60_DT & $0.78 \pm 0.11^{\mathrm{a}}$ & $0.84 \pm 0.14^{\mathrm{a}}$ & $0.82 \pm 0.14^{b}$ & $0.33 \pm 0.03$ & $0.34 \pm 0.04$ & $0.35 \pm 0.04$ \\
\hline \multirow[t]{2}{*}{ T120_DT } & $0.81 \pm 0.11^{b, m}$ & $0.85 \pm 0.14^{b, m}$ & $0.83 \pm 0.13^{c, 1}$ & $0.34 \pm 0.04$ & $0.35 \pm 0.05$ & $0.37 \pm 0.06$ \\
\hline & \multicolumn{3}{|c|}{ Stride Time (s) } & \multicolumn{3}{|c|}{ Cadence (Stride $\cdot \min ^{-1}$ ) } \\
\hline WF_ST & $1.05 \pm 0.08^{\mathrm{a}}$ & $1.07 \pm 0.12^{\mathrm{a}, \mathrm{n}}$ & $1.08 \pm 0.12^{b, m}$ & $114.79 \pm 8.68^{a}$ & $113.55 \pm 12.27^{\mathrm{c}, \mathrm{n}}$ & $112.74 \pm 11.91 \mathrm{~b}, \mathrm{~d}, \mathrm{~m}$ \\
\hline T60_ST & $1.06 \pm 0.11^{\mathrm{a}}$ & $1.09 \pm 0.12^{\mathrm{a}, \mathrm{h}}$ & $1.10 \pm 0.12^{b}$ & $113.77 \pm 10.01^{\mathrm{a}}$ & $111.35 \pm 12.10^{\mathrm{c}, \mathrm{i}}$ & $109.92 \pm 11.32 \mathrm{~b}, \mathrm{~d}$ \\
\hline T120_ST & $1.08 \pm 0.11^{\mathrm{a}}$ & $1.14 \pm 0.14^{\mathrm{c}, \mathrm{n}, \mathrm{h}}$ & $1.13 \pm 0.13^{\mathrm{a}, \mathrm{m}}$ & $112.16 \pm 9.96^{b}$ & $106.90 \pm 12.98^{\mathrm{a}, \mathrm{i}, \mathrm{n}}$ & $107.04 \pm 12.10^{\mathrm{a}, \mathrm{m}}$ \\
\hline WF_DT & $1.09 \pm 0.10^{\mathrm{a}, 1}$ & $1.13 \pm 0.11^{\mathrm{a}, \mathrm{n}}$ & $1.13 \pm 0.12^{b, n}$ & $110.94 \pm 10.08^{\mathrm{a}, \mathrm{m}}$ & $106.76 \pm 10.79 \mathrm{c}, \mathrm{n}$ & $106.79 \pm 10.92^{b, m}$ \\
\hline T60_DT & $1.11 \pm 0.13^{a}$ & $1.18 \pm 0.13^{\mathrm{a}}$ & $1.18 \pm 0.13^{\mathrm{b}}$ & $108.88 \pm 12.57^{\mathrm{a}, \mathrm{g}}$ & $102.94 \pm 11.55^{\mathrm{c}}$ & $103.04 \pm 11.02^{b}$ \\
\hline T120_DT & $1.14 \pm 0.12^{\mathrm{a}, 1}$ & $1.20 \pm 0.15^{\mathrm{c}, \mathrm{n}}$ & $1.20 \pm 0.14^{\mathrm{a}, \mathrm{n}}$ & $105.84 \pm 10.87^{b, g, m}$ & $101.00 \pm 12.46^{\mathrm{a}, \mathrm{n}}$ & $101.44 \pm 11.97^{\mathrm{a}, \mathrm{m}}$ \\
\hline
\end{tabular}

CR: control group; PDNA: Parkinson's disease not affected side; PDA: Parkinson's disease more affected side. WF: walking forward; T60: turning at $60^{\circ} ;$ T120: turning at 120 ${ }^{\circ}$. ST: single task; DT: dual task. ${ }^{\mathrm{a}}=p<0.05,{ }^{\mathrm{b}}=p<0.01,{ }^{\mathrm{c}}=p<0.001$ : significant difference by comparing ST to DT. ${ }^{\mathrm{d}}=p<0.05$ : significant difference by comparing the WF to T60. ${ }^{\mathrm{g}}=p<0.05$;

$\mathrm{h}=p<0.01,{ }^{\mathrm{i}}=p<0.001$ : significant difference by comparing the T60 to T120. ${ }^{1}=p<0.05,{ }^{\mathrm{m}}=p<0.01,{ }^{\mathrm{n}}=p<0.001$ : significant difference by comparing the WF to T120.

Table 3. Step frequency, stride length and walking speed at single and dual tasking in all directions. Data are means \pm SD.

\begin{tabular}{|c|c|c|c|c|c|c|c|c|c|}
\hline \multirow[b]{2}{*}{$\begin{array}{l}\text { Walking } \\
\text { Direction }\end{array}$} & \multicolumn{3}{|c|}{ Step Frequency $(\mathrm{Hz})$} & \multicolumn{3}{|c|}{ Stride Length (m) } & \multicolumn{3}{|c|}{ Walking Speed $\left(\mathrm{m} \cdot \mathrm{s}^{-1}\right)$} \\
\hline & CR & PDNA & PDA & CR & PDNA & PDA & CR & PDNA & PDA \\
\hline WF_ST & $0.95 \pm 0.08^{a}$ & $0.95 \pm 0.10^{\mathrm{c}, \mathrm{n}}$ & $0.94 \pm 0.10^{\mathrm{b}, \mathrm{m}}$ & $1.34 \pm 0.10^{\mathrm{a}, \mathrm{n}, \#,{ }^{\circ}}$ & $1.23 \pm 0.14^{\mathrm{b}, \mathrm{n}, \#}$ & $1.24 \pm 0.14^{\mathrm{c}, \mathrm{n}^{\circ}}$ & $1.28 \pm 0.12^{\mathrm{c}, \mathrm{m}, \#_{,}^{\circ}}$ & $1.17 \pm 0.21^{b, f, n, \#}$ & $1.17 \pm 0.21^{\mathrm{b}, \mathrm{e}, \mathrm{n},}$ \\
\hline T60_ST & $0.95 \pm 0.08^{a}$ & $0.93 \pm 0.10^{\mathrm{c}, \mathrm{h}}$ & $0.92 \pm 0.10^{b}$ & $1.33 \pm 0.08^{\mathrm{b}, \mathrm{h}, \# \mathrm{f}^{\circ}}$ & $1.20 \pm 0.14^{\mathrm{b}, \mathrm{i}, \#}$ & $1.23 \pm 0.16^{\mathrm{c}, \mathrm{i}^{\circ}}$ & $1.26 \pm 0.12^{\mathrm{c}, \mathrm{i}, \#,^{\circ}}$ & $1.06 \pm 0.17^{\mathrm{f}, \mathrm{i}, \mathrm{i}, \mathrm{H}}$ & $1.06 \pm 0.18^{\mathrm{e}, \mathrm{i}^{\circ}}$ \\
\hline T120_ST & $0.93 \pm 0.08^{b}$ & $0.89 \pm 0.11 \mathrm{a}, \mathrm{h}, \mathrm{n}$ & $0.89 \pm 0.10^{\mathrm{a}, \mathrm{m}}$ & $1.24 \pm 0.07^{\mathrm{a}, \mathrm{h}, \mathrm{n}, \#, \mathrm{f}^{\circ}}$ & $1.05 \pm 0.13^{i, n, \#}$ & $1.05 \pm 0.11^{\mathrm{i}, \mathrm{n},}$, & $1.15 \pm 0.12^{\mathrm{b}, \mathrm{i}, \mathrm{m}, \#, \mathrm{o}}$ & $0.95 \pm 0.15$ i,n,\# & $0.95 \pm 0.14^{\mathrm{i}, \mathrm{n},}$ \\
\hline WF_DT & $0.92 \pm 0.08^{\mathrm{a}, \mathrm{m}}$ & $0.89 \pm 0.09^{c, n}$ & $0.89 \pm 0.09^{b, m}$ & $1.27 \pm 0.06^{\mathrm{a}, \mathrm{n}, \#,{ }^{\circ}}$ & $1.14 \pm 0.12^{b, n, \#}$ & $1.15 \pm 0.13^{\mathrm{c}, \mathrm{n},}$ & $1.18 \pm 0.10^{c, n, \#, o}$ & $1.09 \pm 0.17^{\mathrm{b}, \mathrm{d}, \mathrm{n}, \#}$ & $1.11 \pm 0.18^{\mathrm{b}, \mathrm{n}, \mathrm{o}}$ \\
\hline T60_DT & $0.91 \pm 0.10^{\mathrm{a}, \mathrm{g}}$ & $0.86 \pm 0.10^{c}$ & $0.86 \pm 0.09^{b}$ & $1.26 \pm 0.07^{\mathrm{b}, \mathrm{i}, \#,{ }^{\circ}}$ & $1.14 \pm 0.15^{\mathrm{b}, \mathrm{i}, \#}$ & $1.14 \pm 0.15^{\mathrm{c}, \mathrm{i}_{\mathrm{o}}^{\circ}}$ & $1.14 \pm 0.15^{\mathrm{c}, \mathrm{i}, \#,,_{i}^{\circ}}$ & $1.03 \pm 0.18^{\mathrm{d}, \mathrm{i}, \mathrm{H}, \mathrm{H}}$ & $1.06 \pm 0.17^{\mathrm{i},}$ \\
\hline T120_DT & $0.88 \pm 0.09^{b, g, m}$ & $0.84 \pm 0.10^{\mathrm{a}, \mathrm{n}}$ & $0.84 \pm 0.10^{\mathrm{a}, \mathrm{m}}$ & $1.18 \pm 0.08^{\mathrm{a}, \mathrm{i}, \mathrm{n}, \#, \mathrm{i}^{\circ}}$ & $1.02 \pm 0.16^{\mathrm{i}, \mathrm{n}, \#}$ & $1.01 \pm 0.16^{\mathrm{i}, \mathrm{n},}$ & $1.04 \pm 0.14^{\mathrm{b}, \mathrm{i}, \mathrm{n}, \#, \mathrm{o}^{\circ}}$ & $0.89 \pm 0.16^{\mathrm{i}, \mathrm{n}, \#}$ & $0.89 \pm 0.14^{\mathrm{i}, \mathrm{n},}$ \\
\hline
\end{tabular}

CR: control group; PDNA: Parkinson's disease not affected side; PDA: Parkinson's disease more affected side. WF: walking forward; T60: turning at $60^{\circ}$; T120: turning at $120^{\circ}$. ST: single task; DT: dual task. ${ }^{\mathrm{a}}=p<0.05,{ }^{\mathrm{b}}=p<0.01,{ }^{\mathrm{C}}=p<0.001$ : significant difference by comparing ST to DT. ${ }^{\mathrm{d}}=p<0.05,{ }^{\mathrm{e}}=p<0.01,{ }^{\mathrm{f}}=p<0.001$ : significant difference by comparing the WF to T60. ${ }^{\mathrm{g}}=p<0.05 ;{ }^{\mathrm{h}}=p<0.01,{ }^{\mathrm{i}}=p<0.001$ : significant difference by comparing the T60 to T120. ${ }^{\mathrm{m}}=p<0.01,{ }^{\mathrm{n}}=p<0.001$ : significant difference by comparing the WF to T120.

${ }^{\#}=p<0.05$ : significant difference by comparing the CR group to the PDNA group. ${ }^{\circ}=p<0.05$ : significant difference by comparing the CR group to the PDA group. 
The stride length was affected by group $(\mathrm{F}(2,24)=4.415, p<0.05)$, task $(\mathrm{F}(1,24)=41.213$, $p<0.001)$ and direction $(\mathrm{F}(2,48)=132.916, p<0.001)$. In particular, healthy controls walked with longer strides when compared to patients, whereas no differences were observed among the sides in the pathological group. All groups reduced their stride lengths during the dual task condition, and the $120^{\circ}$ turn showed the lowest value compared with the other conditions.

Additionally, the walking velocity changed with group $(\mathrm{F}(2,24)=2.764, p<0.05)$, task $(\mathrm{F}(1,24)=21.818, p<0.001)$ and direction $(\mathrm{F}(2,48)=104.061, p<0.001)$. In general, controls walked faster than patients, and the latter group showed similar values in both sides. Furthermore, the larger the turning the lower the velocity: the $120^{\circ}$ turn showed the lowest velocity value compared to other directions.

The calculated LRI index significantly changed with group $(\mathrm{F}(2,24)=4.672, p<0.05)$, task $(\mathrm{F}(1,24)=14.712, p<0.001)$ and direction $(\mathrm{F}(2,48)=70.937, p<0.001)$. Because of the lack of a significant difference, the data of the PDNA and PDA were pooled together. Our data confirmed that patients walked with a lower LRI compared to controls in all the investigated conditions because of their reduced walking speed, and such a pattern is more pronounced at turning $120^{\circ}$ (Figure 4).

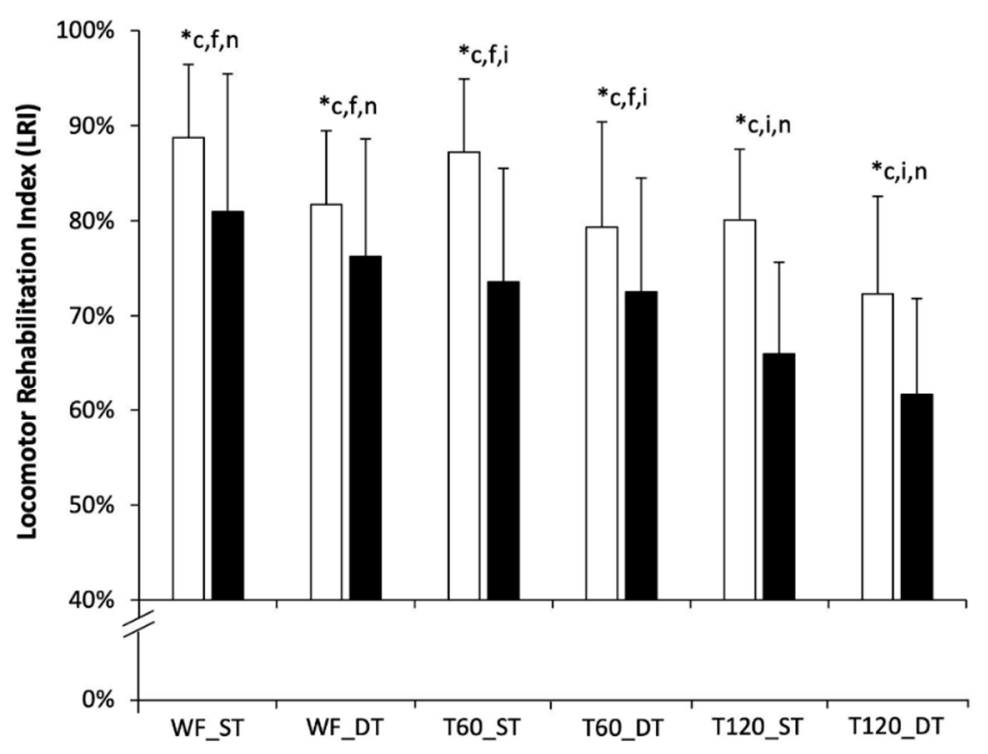

Figure 4. Comparison of locomotor rehabilitation index values between the control group (white bars) and the pathological group (black bars), for the forward direction (WF), turning $60^{\circ}$ (T60) and turning $120^{\circ}$ (T120), in both single (ST) and dual (DT) tasks. Average values \pm SD have been reported; data of the PDNA and PDA were pooled together. A significant post-hoc test has been reported: ${ }^{*}=p<0.05$ by comparing the control group to the pathological one; $c=p<0.001$ : significant difference by comparing the ST to DT; $\mathrm{f}=p<0.001$ : significant difference by comparing WF to T60; $\mathrm{i}=p<0.001$ : significant difference by comparing T60 to T120; $n=p<0.001$ : significant difference by comparing WF to T120 (same legend as in Tables 2 and 3).

Finally, iso-velocity curves were calculated for each group and condition to understand the complex interaction between stride length and frequency in determining the walk velocity (Figure 5).

During the straight gait (Figure 5, panel a), in single tasking, the patients with PD used the same step frequency compared to controls, but they walked with a shorter stride length. As a consequence, their walking velocities were lower. During the dual task, all curves moved down and to the left: this implied a decrease in the walking speed for controls and patients, and the ratio between the stride length and step frequency was the same. 

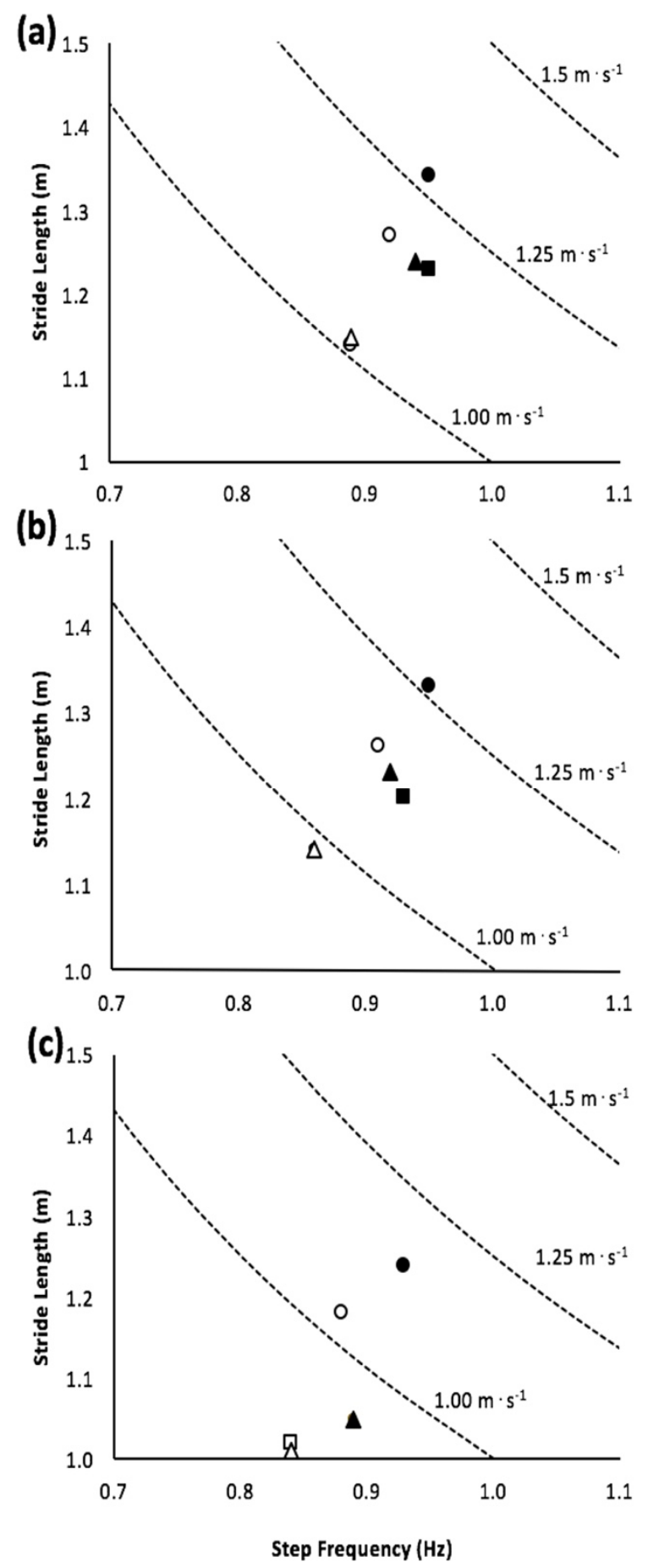

Figure 5. Stride length is plotted as a function of the step frequency (i.e., the iso-velocity curves): (a) walking forward (WF); (b) turning at $60^{\circ}$ (T60); (c) turning at $120^{\circ}$ (T120). The symbols refer to different groups as follows: CRs in the single task $\bullet$; CRs in the dual task $\bigcirc$; the PDNA in the single task $\mathbf{\square}$; PDNA in the dual task $\square$; PDA in the single task $\mathbf{\Delta}$; PDA in the dual task $\Delta$. For PDNA sometimes the symbols are not seen because they exactly coincide with the data of the other two groups.

This trend occurs similarly in turning (Figure 5, panels b and c), independently of group and task. Importantly, the most significant reduction in the walking velocity occurred while turning $120^{\circ}$ and confirms that a larger angle of turning leads to a lower walking velocity. 


\section{Discussion}

The present study focused on the effects of dual task and turning on the kinematic parameters in mild to moderate Parkinson's disease. We hypothesized that the simple cognitive and mechanical tasks will display similar effects in both populations, while the combination of these two stimuli will show a higher impact on patients. We found that: (i) the temporal walking parameters were affected by the mental task, as well as by the mechanical demand (turning), but no significant differences among populations were observed. On the contrary, the stride length and walking speed were lower in PD patients compared to controls; (ii) the turning task had the capability to alter the walking parameters, especially in people with $\mathrm{PD}$, and the major changes in the walking strategy have been observed while turning at a larger angle $\left(120^{\circ}\right)$; (iii) the combination of the cognitive and the mechanical task was challenging for patients. Indeed, their stride length and walking velocity showed significant alterations compared to controls in all walking conditions; finally, (iv) no significant differences were observed between the not affected/more affected side in all the investigated parameters, suggesting an equal symmetry between the right and left body side.

Taking them together, our results highlighted that a simple mental task alone is not sizeable enough to alter the walking strategy in patients with PD with mild to moderate impairments, whereas the combination of this cognitive task with a change of direction has the capability to modify the walking strategy, especially with a higher turning angle $\left(120^{\circ}\right)$.

\subsection{Effects on Gait Variables: A Task Comparison}

In single tasking, our data confirmed that patients with mild to moderate PD walked with a reduced gait velocity and a shorter step length compared to controls. Therefore, patients showed a lower locomotor index rehabilitation if compared to controls with no evident differences between the not affected and more affected side. This finding suggests that the mild to moderate pathology compromises, in a similar way, the gait kinematics of the inferior limbs (e.g., it did not compromise the symmetry among body sides). Since, postural control and gait are linked to cognitive function both in healthy and pathological subjects [18,22,42], it is possible to assume that PD patients reduced their stride length in order to increase the time spent on the ground, increasing the walking stability.

As we hypothesized, a simple dual task condition (repeating the days of the week backwards) affected both groups similarly: all participants increased the ground contact (and the cycle time) and decreased their cadence and frequency $[12,19]$. This finding endorses that subjects tried to maintain their postural stability by spending more time on the ground, as this would prevent the risk of falling [18]. The lack of a difference among groups confirms that, by adding a cognitive load, a low disease severity could not play a major role in determining motor impairments [23]. In addition, the high focus on the additional task means a larger proportion of the attentional capacity is at the expense of walking performance: people walked even more slowly with much shorter steps [7,12,15,22,43-46]. This "compensatory strategy" could be useful in achieving a greater control of gait and balance disruption [20], and in counterbalancing the fluctuations of the center of mass.

Finally, the similar ratio between the stride length and step frequency means that subjects did not change their stride pattern. This latter outcome suggests that the simple cognitive task was probably not too demanding for all participants. More complex cognitive tasks (i.e., concurrent loads, mental tracking) would probably point out the gap among groups $[19,20]$.

\subsection{Effects on Gait Variables: A Direction Comparison}

In the present study, we investigated two turning angles that are very common during daily activity [38]: the first $\left(60^{\circ}\right)$ represents a simple turn and the other $\left(120^{\circ}\right)$ a more difficult turn.

Our spatiotemporal data are in line with the previous literature $[8,10,18,21]$. With respect to directions, whereas healthy participants were impacted by the $120^{\circ}$ turn, $\mathrm{PD}$ patients were also affected 
by the $60^{\circ}$ turn, but only for the walking velocity. Additionally, in this case, no appreciable differences between the not affected and more affected side were observed.

Generally, the $120^{\circ}$ turning is characterized by an increased support time and a reduced number of strides (i.e., cadence) and frequency, as well as a decreased speed and length. This angle requires additional attentional resources: in fact, it relies more heavily on proprioception (i.e., directed by the basal ganglia function) than both forward walking and the $60^{\circ}$ turn [47]. By considering the mechanical approach, the impact of a larger turning could be explained by the kinetics of the movement. Indeed, to move into a larger angle of turn, the subjects decreased their speed more (just for a greater angle of turn) and, probably, used their turn foot as "pivot foot". When the turn angle increased, the ankle plantar flexion moment (and its peak) increased and the external rotators of the lower extremity played a much greater role than in straight walking [48-50]. These alterations of the plantar flexors have been accomplished with a reduced ankle power generated in the pre-swing phase (push-off power). Therefore, the larger the angle of turn the higher the mechanical demand. As a result, PD patients tended to reduce the step length and to increase the contact time primarily to improve the stability of the body. They showed an initial alteration of the walking pattern at a $60^{\circ}$ turn, but only the walking velocity was affected. On the other hand, a $120^{\circ}$ turn showed evident differences when compared to the straight direction in terms of both the temporal and spatial parameters; this finding supports the idea of a more challenging stimulus.

Therefore, whereas the $60^{\circ}$ turn could represent a not suitable training stimulus, the $120^{\circ}$ may be a good challenge for people with PD. As expected, all gait alterations are exacerbated during walking with a combination of the two stimuli, especially in PD patients.

\subsection{Effects on Gait Variables: Cognitive Task and Mechanical Task}

The combined effects of dual (cognitive) and mechanical (turn) tasks represent an important training stimulus in people with PD. Indeed, our data shows that the concomitant presence of a simple mental and turning $\left(60^{\circ}\right)$ task produced only a marginal effect on the main kinematics. In particular, the timing parameters showed no significant differences compared with the straight line, and the differences between the single and dual task are comparable to the ones obtained for healthy subjects. Furthermore, even the step length and the step frequency showed a similar trend.

On the contrary, the matching between the same mental task and a more complex mechanical demand $\left(120^{\circ}\right.$ turn) played a greater "destructive" impact especially in patients with PD. Indeed, their temporal and spatial variables showed a much more marked gap than the controls' ones.

Our results were based on a relatively small heterogeneous sample of disabled patients, who lived independently in the community. Therefore, further researches are necessary to extend these findings to a larger sample (i.e., patients with more severe gait deficits or episodes of freezing), or to other conditions (i.e., OFF phase performance).

\section{Conclusions}

Our data showed that a mechanical task (i.e., turning) has the potential to modify gait strategy in people with Parkinson's disease, without changes in symmetry of the lower limbs. Of greatest interest, the concomitant presence of a mechanical task and a simple cognitive task did not produce a further impairment of this gait strategy. Therefore, using the investigated combined condition (turning and repeating the days of the week backwards) could represent a significant training stimulus in such patients. Indeed, the improvement of the mental and physical characteristics is very important in improving the functionality of patients at the early stages of their pathology.

Author Contributions: Conceptualization, F.N., F.B., A.M., M.B.; methodology, F.N., A.M.; software, F.N., E.B.; data curation, F.N., E.B., A.M.; writing-original draft preparation, F.N., A.M., M.B.; writing—review and editing, F.N., A.M., M.B. All authors have read and agreed to the published version of the manuscript.

Funding: This research received no external funding. 
Acknowledgments: We would like to thank Alessandro Corsi, Gianluca Fedel and Davide Nisi for their help in data collection, and the subjects for participating in the study.

Conflicts of Interest: The authors acknowledge that there are no conflicts of interest pertaining to this manuscript.

\section{References}

1. De Lau, L.M.; Breteler, M.M. Epidemiology of Parkinson's disease. Lancet Neurol. 2016, 5, 525-535. [CrossRef]

2. Kelly, V.E.; Eusterbrock, A.J.; Shumway-Cook, A. A review of dual-task walking deficits in people with Parkinson's disease: Motor and cognitive contributions, mechanisms, and clinical implications. Parkinsonism Disord. 2012, 2012, 918719. [CrossRef] [PubMed]

3. Cummings, J.L. Intellectual impairment in Parkinson's disease: Clinical, pathological, and biochemical correlates. J. Ger. Psychiatry Neurol. 1988, 1, 24-36. [CrossRef] [PubMed]

4. Creaby, M.W.; Cole, M.H. Gait characteristics and falls in Parkinson's disease: A systematic review and meta-analysis. Parkinsonism Related Disord. 2018, 57, 1-8. [CrossRef]

5. Kelly, V.E.; Eusterbrock, A.J.; Shumway-Cook, A. The effects of instructions on dual-task walking and cognitive task performance in people with Parkinson's disease. Parkinsonism Dis. 2012. [CrossRef]

6. Nocera, J.R.; Roemmich, R.; Elrod, J.; Atlmann, L.J.P.; Hass, C.J. Effects of cognitive task on gait initiation in Parkinson disease: Evidence of motor prioritization? J. Rehabil. Res. Develop. 2013, 50, 699-708. [CrossRef]

7. Rochester, L.; Galna, B.; Lord, S.; Burn, D. The nature of dual-task interference during gait in incident Parkinson's disease. Neuroscience 2014, 265, 83-94. [CrossRef]

8. Morris, M.E.; Iansek, R.; Matyas, T.A.; Summers, J.J. Stride length regulation in Parkinson's disease: Normalization strategies and underlying mechanisms. Brain 1996, 119, 551-568. [CrossRef]

9. Morris, M.E.; Huxham, F.; McGinley, J.; Dodd, K.; Iansek, R. The biomechanics and motor control of gait in Parkinson disease. Clin. Biomech. 2001, 16, 459-470. [CrossRef]

10. Canning, C.G. The effect of directing attention during walking under dual task conditions in Parkinson's disease. Parkinsonism Relat. Disord. 2005, 11, 95-99. [CrossRef]

11. Plotnik, M.; Dagan, Y.; Gurevich, T.; Giladi, N.; Hausdorff, J.M. Effects of cognitive function on gait and dual tasking abilities in patients with Parkinson's disease suffering from motor response fluctuations. Exp. Brain Res. 2011, 208, 169-179. [CrossRef] [PubMed]

12. O'Shea, S.; Morris, M.E.; Iansek, R. Dual task interference during gait in people with Parkinson disease: Effects of motor versus cognitive secondary tasks. Phys. Ther. 2002, 82, 888-897. [CrossRef] [PubMed]

13. Rochester, L.; Hetherington, V.; Jones, D.; Nieuwboer, A.; Willems, A.; Kwakkel, G.; van Wegen, E. Attending to the task: Interference effects of functional tasks on walking in Parkinson's disease and the roles of cognition, depression, fatigue and balance. Arch. Phys. Med. Rehab. 2004, 85, 1578-1585. [CrossRef] [PubMed]

14. Brauer, S.G.; Morris, M.E. Can people with Parkinson's disease improve dual tasking when walking? Gait Posture 2010, 31, 229-233. [CrossRef] [PubMed]

15. Brown, L.A.; de Bruin, N.; Doan, J.B.; Suchowersky, O.; Hu, B. Novel challenges to gait in Parkinson's disease: The effect of concurrent music in single and dual task contexts. Arch. Phys. Med. Rehab. 2009, 90, 1578-1583. [CrossRef] [PubMed]

16. Salazar, R.D.; Ren, X.; Ellis, T.; Toraif, N.; Barthelemy, O.J.; Neargarder, S.; Cronin-Golomb, A. Dual tasking in Parkinson's disease: Cognitive consequences while walking. Neuropsychology 2016, 31, 613-623. [CrossRef]

17. Campbell, C.M.; Rowse, J.L.; Ciol, M.A.; Shumway-Cook, A. The effect of cognitive demand on timed up and Go performance in older adults with and without Parkinson disease. Neurol. Rep. 2003, 27, 2-7. [CrossRef]

18. Camicioli, R.; Oken, B.S.; Sexton, G.; Kaye, J.A.; Nutt, J.G. Verbal fluency task affects gait in Parkinson's disease with motor freezing. J. Geriatr. Psych. Neurol. 1998, 11, 181-185. [CrossRef]

19. Galletly, R.; Brauer, S.G. Does the type of concurrent task affect preferred and cued gait in people with Parkinson's disease. Austr. J. Physiother. 2005, 51, 175-180. [CrossRef]

20. Lapointe, L.L.; Stierwalt, J.A.G.; Maitland, C.G. Talking with walking: Cognitive loading and injurious falls in Parkinson's disease. Intern. J. Speech-Lang. Pathol. 2010, 12, 445-459. [CrossRef]

21. Stegemoller, E.L.; Wilson, J.P.; Hazamy, A.; Shelly, M.C.; Okun, M.S.; Altmann, L.P.; Hass, C.J. Associations between cognitive and gait performance during single- and dual-task walking in people with Parkinson disease. Phys. Ther. 2014, 94, 757-766. [CrossRef] [PubMed] 
22. Yogev, G.; Giladi, N.; Peretz, C.; Springer, S.; Simon, E.S.; Hausdorff, J.M. Dual tasking, gait rhythmicity, and Parkinson's disease: Which aspects of gait are attention demanding? Eur. J. Neurosci. 2005, 22, 1248-1256. [CrossRef] [PubMed]

23. Wild, L.B.; de Lima, D.B.; Balardin, J.B.; Rizzi, L.; Giacobbo, B.L.; Oliveira, H.B.; de Lima, A.; Peyre-Tartaruga, L.A.; Rieder, C.R.; Bromberg, E. Characterization of cognitive and motor performance during dual-tasking in healthy older adults and patients with Parkinson's disease. J. Neurol. 2013, 260, 580-589. [CrossRef] [PubMed]

24. Hong, M.; Perlmutter, J.S.; Earhart, G.M. A kinematic and electromyographic analysis of turning in people with Parkinson disease. Neurorehabil. Neural Repair 2009, 23, 166-176. [CrossRef] [PubMed]

25. Stack, E.; Jupp, K.; Ashburn, A. Developing methods to evaluate how people with Parkinson's disease turn $180^{\circ}$ : An activity frequently associated with falls. Disab. Rehabil. 2004, 26, 478-484. [CrossRef]

26. Stack, E.L.; Ashburn, A.M.; Jupp, K.E. Strategies used by people with Parkinson's disease who report difficulty turning. Parkinson. Relat. Disord. 2006, 12, 87-92. [CrossRef]

27. Adamson, M.B.; Gilmore, G.; Stratton, T.W.; Baktash, N.; Jog, M.S. Medication status and dual tasking on turning strategies in Parkinson disease. J. Neurol. Sci. 2019, 396, 206-212. [CrossRef]

28. Chou, P.; Lee, S. Turning deficits in people with Parkinson's disease. Tzu Chi Med. J. 2013, 25, $200-202$. [CrossRef]

29. Vaugoyeau, M.; Viallet, F.; Mesure, S.; Massion, J. Coordination of axial rotation and step execution: Deficits in Parkinson's disease. Gait Posture 2003, 18, 150-157. [CrossRef]

30. Crenna, P.; Carpinella, I.; Rabuffetti, M.; Calabrese, E.; Mazzoleni, P.; Nemni, R.; Ferrarin, M. The association between impaired turning and normal straight walking in Parkinson's disease. Gait Posture 2007, 26, 172-178. [CrossRef]

31. Willems, A.M.; Nieuwboer, A.; Chavret, F.; Desloovere, K.; Dom, R.; Rochester, L.; Kwakkel, G.; van Wegen, E.; Jones, D. Turning in Parkinson's disease patients and controls: The effect of auditory cues. Mov. Disord. 2007, 22, 1871-1878. [CrossRef] [PubMed]

32. Mellone, S.; Mancini, M.; King, L.A.; Horak, F.B.; Chiari, L. The quality of turning in Parkinson's disease: A compensatory strategy to prevent postural instability? J. Neuroeng Rehabil. 2016, 13, 39. [CrossRef] [PubMed]

33. Bertoli, M.; Della Croce, U.; Cereatti, A.; Mancini, M. Objective measures to investigate turning impairments and freezing of gait in people with Parkinson's disease. Gait Posture 2019, 74, 187-193. [CrossRef] [PubMed]

34. Encarna Micó-Amigo, M.; Kingma, I.; Heinzel, S.; Nussbaum, S.; Heger, T.; Lummel, R.C.V.; Dieën, J.H.V. Dual vs. Single Tasking during Circular Walking: What Better Reflects Progression in Parkinson's Disease? Front. Neurol. 2019. [CrossRef]

35. Spildooren, J.; Vercruysse, S.; Desloovere, K. Freezing of gait in Parkinson's disease: The impact of dual-tasking and turning. Mov. Disord. 2010, 25, 2563-2570. [CrossRef] [PubMed]

36. Bayot, M.; Dujardin, K.; Tard, C.; Defebvre, L.; Bonnet, C.T.; Allart, E.; Delval, A. The interaction between cognition and motor control: A theoretical framework for dual-task interference effects on posture, gait initiation, gait and turning. Clin. Neurophys. 2018, 48, 361-375. [CrossRef]

37. Hackney, M.E.; Earhart, G.M. The effects of a secondary task on forward and backward walking in Parkinson disease. Neurorehabil. Neural Repair 2010, 24, 97-106. [CrossRef]

38. Patla, A.E.; Prentice, S.D.; Robinson, C.; Neufeld, J. Visual control of locomotion: Strategies for changing direction and for going over obstacles. J. Exp. Psychol. 1991, 17, 603-634. [CrossRef]

39. Hughes, A.J.; Daniel, S.E.; Kilford, L.; Lees, A.J. Accuracy of clinical diagnosis of idiopathic Parkinson's disease: A clinico-pathological study of 100 cases. J. Neurol. Neurosurg. Psychiatry 1992, 55, 181-184. [CrossRef]

40. Schenkman, M.L.; Clark, K.; Xie, T.; Kuchibhatla, M.; Shinberg, M.; Ray, L. Spinal movement and performance of a standing reach task in participants with and without Parkinson disease. Phys. Ther. 2001, 81, 1400-1411. [CrossRef]

41. Movement Disorder Society Task Force on Rating Scales for Parkinson's Disease. The Unified Parkinson's Disease Rating Scale (UPDRS): Status and recommendations. Mov. Disord. 2003, 18, 738-750. [CrossRef] [PubMed]

42. Peyre-Tartaruga, L.A.; Monteiro, E.P. A new integrative approach to evaluate pathological gait: Locomotor rehabilitation index. Clin. Transl. Degener. Dis. 2016, 1, 86-90. [CrossRef] 
43. Woollacott, M.; Shumway-Cook, A. Attention and the control of posture and gait: A review of an emerging area of research. Gait Posture 2002, 16, 1-14. [CrossRef]

44. Plotnik, M.; Giladi, N.; Hausdorff, J.M. Bilateral coordination of gait and Parkinson's disease: The effects of dual tasking. J. Neurol. Neurosurg. Psych. 2009, 80, 347-350. [CrossRef]

45. Hausdorff, J.M.; Balash, J.; Giladi, N. Effects of cognitive challenge on gait variability in patients with Parkinson's disease. J. Geriatr. Psych. Neurol. 2003, 16, 53-58. [CrossRef] [PubMed]

46. De Melo Roiz, R.; Avezedo Cacho, E.W.; Macedo Pazinatto, M.; Guimaraes Reis, J.; Cliquet, A.; Barasnevicius-Quagliato, E.M.A. Gait analysis comparing Parkinson's disease with healthy elderly subjects. Arq. Neuropsiquiatr. 2010, 68, 81-86. [CrossRef]

47. Sofuwa, O.; Nieuwboer, A.; Desloovere, K.; Willems, A.M.; Chavret, F.; Jonkers, I. Quantitative gait analysis in Parkinson's disease: Comparison with a healthy control group. Arch. Phys. Med. Rehabil. 2005, 86, 1007-1013. [CrossRef]

48. Taylor, M.J.D.; Dadbnichki, P.; Strike, S.C. A three-dimensional biomechanical comparison between turning strategies during the stance phase of walking. Hum. Mov. Sci. 2005, 24, 558-573. [CrossRef]

49. Segal, A.; Orendurff, M.; Flick, K.; Berge, J.; Klute, G. Ankle biomechanics during a spin turn. In Proceedings of the 28th Annual Meeting of the American Society of Biomechanics, Boulder, CO, USA, 15 July 2004; p. 168.

50. Xu, D.; Chow, J.W.; Wang, Y.T. Effects of turn angle and pivot foot on lower extremity kinetics during walk and turn actions. J Appl. Biomech. 2006, 22, 74-79. [CrossRef]

(C) 2020 by the authors. Licensee MDPI, Basel, Switzerland. This article is an open access article distributed under the terms and conditions of the Creative Commons Attribution (CC BY) license (http://creativecommons.org/licenses/by/4.0/). 